\title{
Association between body size, weight change and depression: systematic review and meta-analysis
}

Sun Jae Jung, Hyung-taek Woo, Sooyoung Cho, Kyounghoon Park, Seokhun Jeong,

Yu Jin Lee, Daehee Kang and Aesun Shin

\section{Background}

The association between body size, weight change and depression has not been systematically summarised, especially for individuals who are underweight.

\begin{abstract}
Aims
To conduct a systematic review and a meta-analysis to examine the association between indices of body size, weight change and depression.
\end{abstract}

\section{Method}

A total of 183 studies were selected. Fully adjusted hazard ratios (HRs) or odds ratios (ORs) were extracted. A total of 76 studies contributed to data synthesis with a random-effect model, and subgroup analyses were conducted to evaluate the effect of potential moderators.

\section{Results}

In cohort studies, underweight at baseline increased the risk of subsequent depression ( $\mathrm{OR}=1.16,95 \% \mathrm{Cl} 1.08-1.24)$.
Overweight (BMl $25-29.9 \mathrm{~kg} / \mathrm{m}^{2}$ ) showed no statistically significant relationship with depression overall; however, the subgroup analyses found different results according to gender (men: $\mathrm{OR}=0.84,95 \% \mathrm{Cl} 0.72-0.97$, women: $\mathrm{OR}=1.16$, $95 \% \mathrm{Cl} 1.07-1.25)$. In cross-sectional designs, obesity with $\mathrm{BMI}>40 \mathrm{~kg} / \mathrm{m}^{2}$ showed a greater pooled odds ratio than obesity with $\mathrm{BMI}>30 \mathrm{~kg} / \mathrm{m}^{2}$.

\section{Conclusions}

Both underweight and obesity increase the risk of depression. The association between overweight and depression differs by gender.

\section{Declaration of interest}

None.

\section{Copyright and usage}

(c) The Royal College of Psychiatrists 2017.
Depression is a condition that represents a burden worldwide. ${ }^{1}$ Obesity has consistently been shown to be a risk factor for depression, and several systematic reviews and meta-analyses have evaluated the association between the two. A recent meta-analysis conducted with 15 prospective studies showed a significantly increased overall odds ratio (OR) of depression in an obese population, ${ }^{2}$ yet this meta-analysis only included studies conducted in Western populations, and no considerations of other ethnicities, such as Asians, were made. In eight of the previous systematic reviews and meta-analyses, ${ }^{3-8}$ there was no analysis focusing on people who were underweight and the studies were limited to certain geographical areas. In addition, the association between weight change and depression has not been properly summarised. It is uncertain whether being underweight affects depression in a larger population or whether being obese is always associated with depression. Both obesity and underweight could be related to depression because the diagnostic criteria in DSM-IV includes increased or decreased appetite as a symptom of depression, which can be related to obesity or underweight. Both conditions can provoke a negative body image that can result in psychological distress and low self-esteem. ${ }^{9}$ Therefore, we aimed to conduct a systematic review and meta-analysis on all available epidemiological studies, including randomised controlled trials (RCTs), cohort and cross-sectional studies, to evaluate the association between depression and indices of body size covering not only obesity but also underweight. In addition, the relationship between weight change and subsequent depression was assessed. Stratified analysis by gender, age, geographical area, definition of depression and study design was conducted. The participants, interventions, comparisons outcomes and study design (PICOS) in this study are detailed in online Table DS1 (see also online supplement DS1 for the Meta-analysis of Observational Studies in Epidemiology (MOOSE) checklist).

\section{Method}

\section{Study selection}

A computerised systematic literature search of the PubMed, Embase and Cochrane library databases was performed to identify studies published prior to 10 March 2015. Search keywords were for body size or weight change ("body weight", "weight change", "body mass index", "obesity", "adiposity", "thinness", "underweight" or "overweight", "waist-hip ratio" and "waist circumference") and depression ("depressive disorder", "dysthymic disorder", "seasonal affective disorder" or "depression") combined. Hand-searching of the references was used for inclusion of additional articles. There was no language restriction. Additional studies were identified from a manual search of all relevant references. Articles were first screened by a review of their titles, and a full-text review was then conducted. Every selection stage involved five independent researchers (four medical doctors (S.J.J., H.-t.W., K.P. and S.J.) and one graduate student (S.C.) in epidemiology). Every article was independently checked by two researchers, and if opinion differed, a third researcher mediated in the final selection. Study data were extracted by two independent researchers (S.J.J. and H.-t.W.). Studies were subdivided into categories according to the study design (RCT, prospective and retrospective cohort, case-control and cross-sectional) and a summary estimate of effect sizes (hazard ratio (HR) or odds ratio).

\section{Inclusion and exclusion criteria}

All the studies were conducted in human populations including entire age groups. Articles measuring body mass index (BMI), waist circumference, waist-to-height ratio, waist-to-hip ratio, body fat or relevant variables such as weight change in relation to known measures of depression as an outcome were included. 
Studies conducted with diagnostic criteria for depression, such as the Diagnostic Interview Schedule (DIS) or Composite International Diagnostic Interview (CIDI), were collected in addition to studies conducted with self-rating scales on depression such as the Beck Depression Inventory (BDI) or the Center for Epidemiologic Studies-Depression Scale (CES-D). We included studies that were conducted using cohort, case-control or cross-sectional designs. If more than two studies were performed in the same population, we chose the study conducted most recently. We excluded case reports, letters, comments and reviews. Studies examining the relationship among body size, weight change and bipolar depression, or studies on depression in relation to pregnancy were also excluded. We excluded non-human experimental studies and studies without a full document (i.e. studies with only an abstract). Additionally, we excluded studies with results that could not be converted to a standardised effect size.

\section{Statistical analysis}

The studies were reported as summary statistics in different ways. Although most of the studies reported odds ratios and their $95 \%$ confidence intervals, some studies reported the associations as beta-coefficients. Additionally, some reported a frequency table only. In studies with a prospective cohort design, hazard ratios were also reported. We grouped the studies according to the study design (RCT, prospective cohort, case-control and cross-sectional study), and all the summary statistics were converted to odds ratios and $95 \%$ confidence intervals, except the results with hazard ratios. If this was not possible, we contacted the study authors by email to obtain the effect sizes as odds ratio values. We used hazard ratio/odds ratio in the final adjustment model. To convert effect sizes and determine pooled mean effect size, we used Review Manager (RevMan) version 5.3 and Stata version 13.0.

As considerable heterogeneity was expected between estimates from the studies, the summary effect size was derived with a random-effect model. We calculated Cochrane's $Q$ and $I^{2}$ to quantify heterogeneity. The degree of heterogeneity was categorised as low, moderate and high with threshold values of $25 \%, 50 \%$ and $75 \%$, respectively. ${ }^{10}$ As we aimed to evaluate the association by demographic variables as possible effect modifiers, we conducted subgroup analysis for gender (men or women), age group among adults ( $18-50$ years or $\geqslant 51$ years), continent of residence (Asia, North America, Europe and other) and definition criteria of depression (clinical diagnostic criteria or self-reporting scales).

Publication bias was assessed by funnel plot. Egger's tests may cause bias when using odds ratios, ${ }^{11}$ and as the majority of the publications included in our analysis used odds ratios, we were unable to assess publication bias.

\section{Quality assessment}

We selected the Risk of Bias Assessment Tool for Nonrandomized Studies (RoBANS) for quality assessment. RoBANS has been validated as a 'fair' assessment tool with moderate reliability and promising validity. ${ }^{12}$ RoBANS is applicable to cross-sectional, case-control and cohort studies and comprises eight items: comparability, participant selection, confounding, exposure measurement, masking of outcome assessments, measurement of outcomes, incomplete outcome and selective reporting of outcomes. Each item is measured as 'high risk of bias', 'low risk of bias' or 'uncertain'. For example, as for the 'confounder' section, each researcher marked an article to be 'high risk of bias' if there were no consideration of the covariates' time varying effect on major hypothesis for cohort studies. For cross-sectional studies, researchers rated 'high risk' when there was no description for major covariates using matching, restriction, stratification or propensity score. Each article was cross-checked by two or more researchers. For the quantitative assessment, we totalled the number of 'high risk of bias' and 'uncertain' items and selected the article as 'low quality' if the sum of the items was greater than two. We calculated pooled odds ratios and the $I^{2}$ value among the 'high quality' and 'low quality' articles and compared the pooled odds ratios between the estimated overall studies and the estimates for 'high-quality' studies.

\section{Results}

\section{Included and excluded studies}

A total of 26868 abstracts were selected from the database search (18 959 from PubMed, 4400 from Embase, 3496 from the Cochrane library, and 13 from hand-searched references). After removing 2744 duplicated publications, a total of 24124 studies were included for review of the title and full text. Studies conducted with irrelevant subjects, animal studies or those that were not original articles were excluded. Studies were excluded in the final stage primarily because their data were unavailable for the meta-analysis. An additional 25 studies were excluded because there were other studies conducted in same population, which was confirmed by two independent researchers (S.J.J. and H.-t.W.). In such cases, we selected the most recent study. A total of 183 studies were included in the final analysis (online Fig. DS1).

Of the total of 183 studies, 8 were RCTs and 72 were cohort studies. With the exception of one study, all studies with a cohort design were conducted with a prospective cohort design. Six studies were conducted using a case-control design, including one nested case-control study in a cohort. A total of 97 studies were cross-sectional studies. In these results, 38 studies applied the World Health Organization's definition of BMI criteria (1 869077 participants). ${ }^{13}$ In 40 studies, depression was diagnosed by a physician or by a structured diagnostic interview such as the CIDI based on ICD-10 and DSM-IV. ${ }^{14}$ In the remaining 143 studies, a self-reported depression scale was used to define depression. A total of 137 studies (1508013 participants) evaluated the link between body size at baseline and development of depression at follow-up, 33 studies (3447413 participants) examined the inverse relationship, and 13 studies (1830228 participants) tested both directions. The characteristics of the selected studies are presented in online Table DS2. A total of 6788834 participants were included in the analysis.

\section{Underweight and subsequent depression}

Table 1 presents the overall and subgroup analysis of the relationship between underweight (BMI $<18.5 \mathrm{~kg} / \mathrm{m}^{2} v$. a reference BMI of $18.5-24.9 \mathrm{~kg} / \mathrm{m}^{2}$ ) and subsequent depression in adult cohort/ cross-sectional studies. The pooled odds ratio for six cohort studies ${ }^{15-20}$ was 1.16 with statistical significance (95\% CI $1.08-$ 1.24 ) and an $I^{2}$ value of $9.3 \%$, suggesting that that there were no substantial systematic deviations between the odds ratios of the studies (Fig. 1). In subgroup analysis, the pooled odds ratio for underweight (BMI $\left.<18.5 \mathrm{~kg} / \mathrm{m}^{2}\right)$ men was $1.21(95 \% \mathrm{CI}$ 1.04-1.40) and the percentage of the total difference across six studies with corresponding data was small to moderate $\left(I^{2}=32.1 \%\right)$. For women who were underweight (BMI $<18.5 \mathrm{~kg} / \mathrm{m}^{2}$ ) the pooled odds ratio was 1.12 (95\% CI $0.98-$ 1.28 ). Whereas in the subgroup in which depression was defined using self-reported scales there was no significant association, in the subgroup in which depression was defined with a clinical diagnostic tool there was a pooled odds ratio of 1.14 (95\% $1.9-$ 1.19) with an $I^{2}$ of $0 \%$. 


\begin{tabular}{|c|c|c|c|c|c|c|}
\hline & $\begin{array}{l}\text { Studies, } n \\
\text { (participants) }\end{array}$ & OR $(95 \% \mathrm{Cl})$ & Q-statistic & $\begin{array}{c}P, \\
\text { heterogeneity }\end{array}$ & $1^{2}$ & $\begin{array}{l}P \text {, between } \\
\text { groups }\end{array}$ \\
\hline \multicolumn{7}{|l|}{ Cohort (adult) } \\
\hline Overall studies & $6(1257109)$ & $1.16(1.08-1.24)$ & 8.82 & 0.357 & 9.3 & \\
\hline \multicolumn{7}{|l|}{ Subgroup analysis } \\
\hline Gender & & & & & & 0.448 \\
\hline Men & 6 (1203101) & $1.21(1.04-1.40)$ & 7.36 & 0.195 & 32.1 & \\
\hline Women & $5(72566)$ & $1.12(0.98-1.28)$ & 3.53 & 0.473 & 0.0 & \\
\hline Age at baseline, $19-50$ & $3(1160028)$ & $1.17(1.10-1.24)$ & 3.40 & 0.333 & 11.9 & \\
\hline Depression definition & & & & & & 0.831 \\
\hline DSM or ICD based & $2(1142220)$ & $1.14(1.09-1.19)$ & 0.11 & 0.945 & 0.0 & \\
\hline Other self-reported & $4(114889)$ & $1.11(0.87-1.41)$ & 8.05 & 0.153 & 37.9 & \\
\hline Continent & & & & & & 0.403 \\
\hline North America & $1(13548)$ & $0.60(0.23-1.62)$ & & & & \\
\hline Europe & $4(1234360)$ & $1.16(1.05-1.28)$ & 6.62 & 0.157 & 39.6 & \\
\hline Asia & $1(9201)$ & $1.31(0.55-3.14)$ & & & & \\
\hline \multicolumn{7}{|l|}{ Cross-sectional (adult) } \\
\hline Overall studies & 20 (453 938) & $1.27(1.10-1.47)$ & 57.93 & 0.001 & 51.7 & \\
\hline \multicolumn{7}{|l|}{ Subgroup analysis } \\
\hline Gender & & & & & & 0.857 \\
\hline Men & $11(212356)$ & $1.29(1.11-1.50)$ & 8.64 & 0.567 & 0.0 & \\
\hline Women & 10 (133751) & $1.26(1.02-1.54)$ & 15.96 & 0.068 & 43.6 & \\
\hline Depression definition & & & & & & 0.876 \\
\hline DSM or ICD based & 5 (127 339) & $1.30(0.91-1.86)$ & 16.39 & 0.003 & 75.6 & \\
\hline Other self-reported & 15 (326599) & $1.26(1.07-1.47)$ & 39.74 & 0.016 & 42.1 & \\
\hline Continent & & & & & & 0.044 \\
\hline North America & 8 (177 691) & $1.31(1.14-1.51)$ & 10.62 & 0.475 & 0.0 & \\
\hline Europe & 3 (202028) & $1.15(0.93-1.43)$ & 7.82 & 0.098 & 48.8 & \\
\hline Asia & $6(31039)$ & $1.21(0.77-1.90)$ & 23.69 & 0.001 & 74.7 & \\
\hline Oceania & $3(43180)$ & $1.88(1.40-2.40)$ & 3.68 & 0.452 & 0.0 & \\
\hline Comorbidity & & & & & & 0.529 \\
\hline Without comorbidity & 19 (453938) & $1.27(1.09-1.49)$ & 54.38 & $<0.001$ & 55.9 & \\
\hline With diabetes & $2(65997)$ & $1.41(1.10-1.80)$ & 0.93 & 0.335 & 0.0 & \\
\hline With metabolic syndrome & $1(210)$ & $0.27(0.01-5.16)$ & & & & \\
\hline With multiple sclerosis & $1(120)$ & $0.97(0.50-1.88)$ & & & & \\
\hline
\end{tabular}

For 20 selected cross-sectional studies ${ }^{18,21-39}$ that investigated the association between underweight and depression, the overall pooled odds ratio was 1.27 (95\% CI 1.10-1.47) with moderate heterogeneity $\left(I^{2}=51.7\right)$. The results of subgroup analyses did not show statistically significant differences.

\section{Overweight and subsequent depression}

As shown in Table 2, a total of six cohort studies ${ }^{15,17,18,20,40,41}$ evaluated the effect of being overweight (BMI $25.0-29.9 \mathrm{~kg} / \mathrm{m}^{2} v$. a reference BMI of $18.5-24.9 \mathrm{~kg} / \mathrm{m}^{2}$ ) on later depression. People in the BMI range of $25-29.9 \mathrm{~kg} / \mathrm{m}^{2}$ had a pooled odds ratio of 1.02 that was not statistically significant (95\% CI 0.84-1.23). However, the results showed significant heterogeneity, with an $I^{2}$ value of $92.0 \%$. This heterogeneity between studies lessened when gender was considered in subgroup analyses. In men who were overweight, the pooled odds ratio was statistically significant $(\mathrm{OR}=0.84,95 \% \mathrm{CI} 0.72-0.97)$. The degree of heterogeneity was moderate $\left(I^{2}=50.6 \%\right)$. The pooled odds ratio showed a protective effect of being overweight in men, whereas women showed an increased odds ratio that was statistically significant $(\mathrm{OR}=1.16$, 95\% CI 1.07-1.25). When the analysis was restricted to women, the heterogeneity decreased substantially to an $I^{2}$ of $11.4 \%$. The pooled odds ratios between men and women who were overweight were significantly different $(P<0.001)$, which indicates that being overweight has a protective effect against depression in men but increases the likelihood of depression in women (Fig. 1).

\section{Obesity and subsequent depression}

Table 3 presents the relationship between being obese $\left(\mathrm{BMI} \geqslant 30 \mathrm{~kg} / \mathrm{m}^{2}\right)$ and depression with a reference BMI of
$18.5-24.9 \mathrm{~kg} / \mathrm{m}^{2}$ in cohort and cross-sectional studies. In six cohort studies ${ }^{15-18,20,40}$ with participants who were obese (a BMI of $30 \mathrm{~kg} / \mathrm{m}^{2}$ or over), the overall pooled odds ratio was 1.13 with marginal significance. Heterogeneity was significant $(P$-heterogeneity $<0.001)$ with an $I^{2}$ value of $82.2 \%$. However, this high heterogeneity decreased to an $I^{2}$ value of $0 \%$ in strata such as women, depression defined with self-reported scales and the European group in the subgroup analysis, with significantly increased pooled odds ratios.

There were 26 cross-sectional studies ${ }^{18,21-23,25-29,31-39,42-49}$ with results for the association between a BMI of $30 \mathrm{~kg} / \mathrm{m}^{2}$ or higher ( $v$. a reference BMI of $18.5-24.9 \mathrm{~kg} / \mathrm{m}^{2}$ ) and depression. The pooled odds ratio in the overall analysis was $1.18(95 \%$ $1.11-1.26)$, with considerable heterogeneity $\left(I^{2}=82.8\right)$. Women showed a higher increase in odds ratio $(\mathrm{OR}=1.41,95 \% \mathrm{CI}$ $1.23-1.63)$ compared with men $(\mathrm{OR}=1.07,95 \%$ CI $0.95-1.19)$ and this difference was statistically significant $(P=0.003)$.

Three cross-sectional studies ${ }^{24,34,50}$ reported results for obesity with a BMI of $40 \mathrm{~kg} / \mathrm{m}^{2}$ or higher compared with a BMI of $18.5-24.9 \mathrm{~kg} / \mathrm{m}^{2}$, and the pooled odds ratio increased to 1.59 (95\% CI 1.12-2.24). The pooled odds ratio was larger than the pooled estimated odds ratio with a BMI of $30 \mathrm{~kg} / \mathrm{m}^{2}$ or over (Table 3).

\section{Waist circumference, weight change and subsequent depression}

The overall pooled odds ratio for people who had a waist circumference over $102 \mathrm{~cm}$ for men or $88 \mathrm{~cm}$ for women was 1.38 and was statistically significant $(95 \% \quad 1.17-1.62$, online 


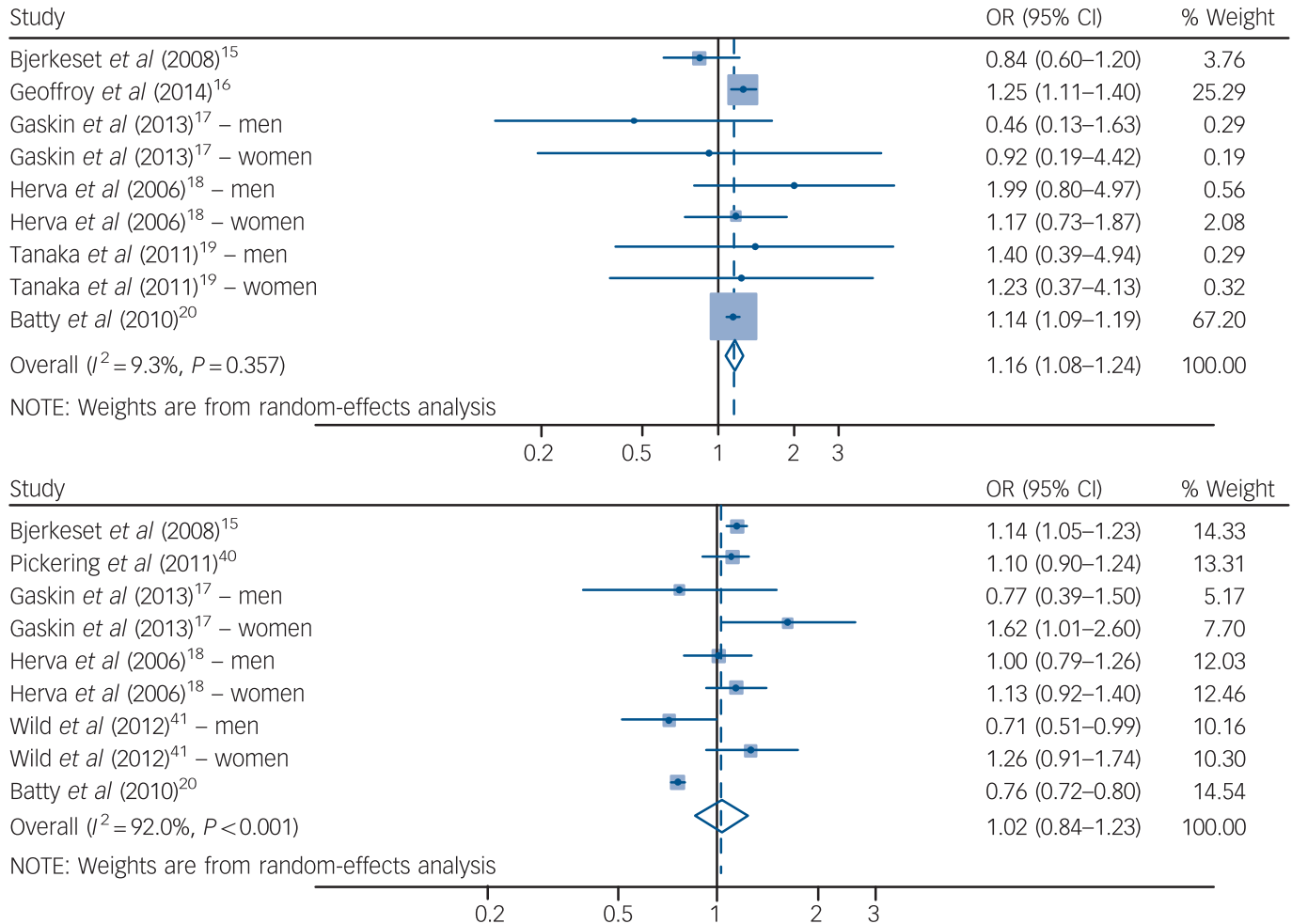

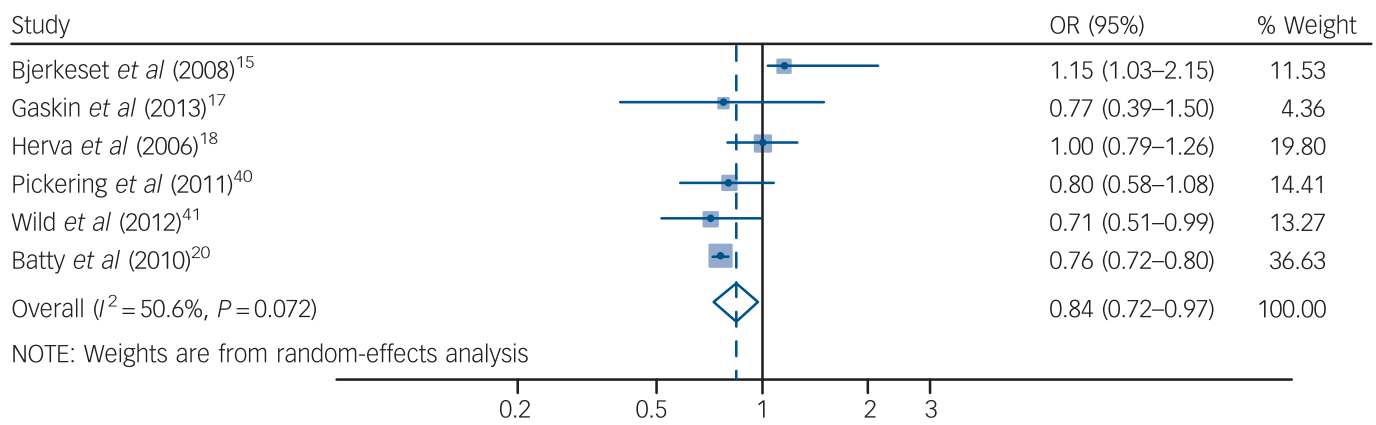

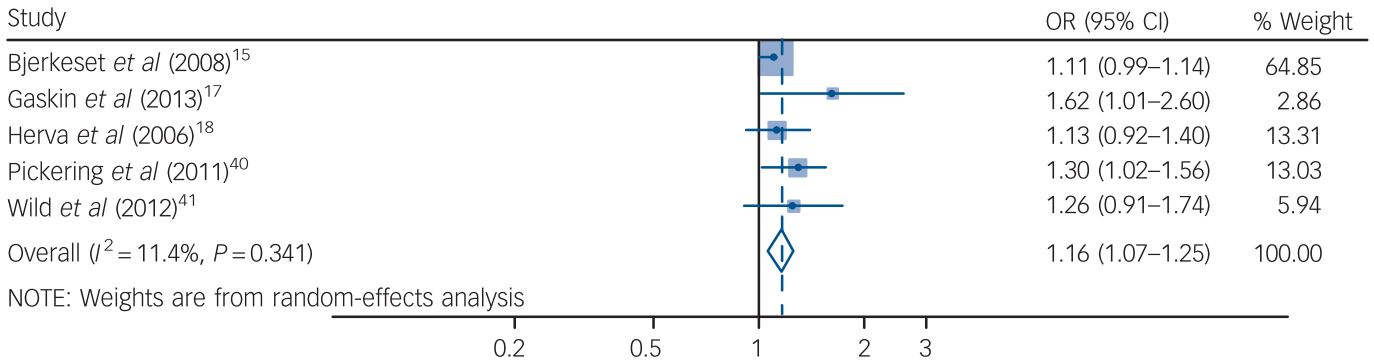

Fig. 1 Forest plot for underweight, overweight and risk of consequent depression in cohort studies.

Table DS3). Online Table DS4 shows the results of overall and subgroup analyses of weight change and subsequent depression in cohort studies. The pooled odds ratio for selected studies that investigated the association between any weight change and subsequent depression was 1.06 with marginal significance (95\% CI 0.99-1.15).

\section{Publication bias}

In testing publication bias using a funnel plot, there was little possibility for publication bias for each analysis, with the exception of evaluating the effect of weight gain alone compared with no weight change in the cohort design and in the association between waist circumference over $102 \mathrm{~cm}$ for men or $88 \mathrm{~cm}$ for women and depression.

\section{Result of quality assessment}

We assessed the 12 cohort studies and 41 cross-sectional studies that were included in the meta-analysis for BMI categories with a reference BMI of 18.5-22.9, waist circumference (men $>102 \mathrm{~cm}$, women $>88 \mathrm{~cm}$ ), weight change and depression. The majority of the studies included in the meta-analysis were found 


\begin{tabular}{|c|c|c|c|c|c|c|}
\hline & $\begin{array}{l}\text { Studies, } n \\
\text { (participants) }\end{array}$ & OR $(95 \% \mathrm{Cl})$ & Q-statistic & $\begin{array}{c}P_{,} \\
\text {heterogeneity }\end{array}$ & $1^{2}$ & $\begin{array}{l}P, \text { between } \\
\text { groups }\end{array}$ \\
\hline \multicolumn{7}{|l|}{ Cohort (adult) } \\
\hline Overall studies & $6(1275140)$ & $1.02(0.84-1.23)$ & 99.97 & $<0.001$ & 92.0 & \\
\hline \multicolumn{7}{|l|}{ Subgroup analysis } \\
\hline Gender & & & & & & $<0.001$ \\
\hline Men & $6(1203664)$ & $0.84(0.72-0.97)$ & 10.11 & 0.072 & 50.6 & \\
\hline Women & $5(71476)$ & $1.16(1.07-1.25)$ & 4.51 & 0.341 & 11.4 & \\
\hline Depression definition & & & & & & 0.387 \\
\hline DSM or ICD based & $2(1167672)$ & $0.90(0.63-1.31)$ & 18.97 & $<0.001$ & 94.7 & \\
\hline Other self-reported & $4(107468)$ & $1.08(0.94-1.24)$ & 12.37 & 0.054 & 51.5 & \\
\hline Continent & & & & & & 0.409 \\
\hline North America & 2 (48 201) & $1.15(0.85-1.56)$ & 3.58 & 0.167 & 44.1 & \\
\hline Europe & $4(1226939)$ & $0.98(0.78-1.23)$ & 86.11 & $<0.001$ & 94.2 & \\
\hline \multicolumn{7}{|l|}{ Cross-sectional (adult) } \\
\hline Overall studies & $29(558525)$ & $0.98(0.91-1.05)$ & 278.96 & $<0.001$ & 83.9 & \\
\hline 1 study excluded (Joseph et al 2013) & $28(558295)$ & $1.02(1.00-1.04)$ & 263.94 & $<0.001$ & 83.3 & \\
\hline \multicolumn{7}{|l|}{ Subgroup analysis } \\
\hline Gender & & & & & & 0.239 \\
\hline Men & 15 (230314) & $0.96(0.88-1.06)$ & 47.26 & $<0.001$ & 68.3 & \\
\hline Women & $14(163351)$ & $1.04(0.95-1.15)$ & 49.06 & $<0.001$ & 71.5 & \\
\hline \multicolumn{7}{|l|}{ Depression definition } \\
\hline DSM or ICD based & $8(185690)$ & $0.86(0.71-1.03)$ & 89.61 & $<0.001$ & 87.7 & \\
\hline Other self-reported & $20(372835)$ & $1.02(0.96-1.09)$ & 122.49 & $<0.001$ & 73.1 & \\
\hline Continent & & & & & & 0.083 \\
\hline North America & $14(274582)$ & $0.97(0.84-1.08)$ & 177.38 & $<0.001$ & 86.5 & \\
\hline Europe & $3(202028)$ & $1.08(0.99-1.16)$ & 11.48 & 0.022 & 65.2 & \\
\hline Middle East & $1(294)$ & $1.65(0.60-4.58)$ & & & & \\
\hline Asia & $7(38441)$ & $0.95(0.75-1.21)$ & 38.41 & $<0.001$ & 76.6 & \\
\hline Oceania & $3(43180)$ & $0.88(0.77-1.01)$ & 6.14 & 0.189 & 34.8 & \\
\hline Comorbidity & & & & & & 0.352 \\
\hline Without comorbidity & 27 (491303) & $0.96(0.89-1.03)$ & 260.68 & $<0.001$ & 85.0 & \\
\hline With diabetes & $3(66291)$ & $2.54(0.64-10.15)$ & 16.36 & $<0.001$ & 87.8 & \\
\hline With metabolic syndrome & $1(210)$ & $0.89(0.46-1.72)$ & & & & \\
\hline With multiple sclerosis & $1(120)$ & $1.23(0.91-1.67)$ & & & & \\
\hline With asthma & $1(601)$ & $1.05(0.64-1.74)$ & & & & \\
\hline
\end{tabular}

to be of 'high quality'; however, two cohort studies ${ }^{5,18}$ and seven cross-sectional studies ${ }^{25-28,47,48,51}$ contained more than two items assessed as 'low quality' (online Tables DS5 and DS6).

We summarised the results according to subgroups of highand low-quality studies and compared the results of the previous overall pooled odds ratios with the summary odds ratios of the high-quality articles. No significant differences were identified between the comparison sets (online Tables DS7 and DS8).

\section{Discussion}

\section{Main findings}

In this study, we found that underweight (BMI $<18.5 \mathrm{~kg} / \mathrm{m}^{2}$ ) increases the risk of depression onset in both longitudinal and cross-sectional settings. In addition, being overweight (BMI $25.0-29.9 \mathrm{~kg} / \mathrm{m}^{2}$ ) decreased the risk of depression in men and increased the risk in women in cohort designs. Being obese $\left(\mathrm{BMI} \geqslant 30 \mathrm{~kg} / \mathrm{m}^{2}\right)$ increased the risk and likelihood of depression in both longitudinal and cross-sectional designs. In cross-sectional studies, people with more severe obesity $\left(\mathrm{BMI} \geqslant 40 \mathrm{~kg} / \mathrm{m}^{2}\right)$ showed a stronger association, which reflects a dose-response pattern.

Overall, the heterogeneity of the cohort design studies was much lower than the heterogeneity of the cross-sectional studies. It should also be noted that results from the cross-sectional studies are not free from bias. Several studies have suggested that depression can influence the validity of self-reported BMI in the obese population and that women especially underestimate their BMI. ${ }^{52}$ In addition, there is a chance of reverse causality especially in cross-sectional studies. It is possible that people with depression lose weight or the weight loss can precede the depressive symptoms. This can also be a problem in cohort studies with a relatively short period of follow-up of depressive symptoms from the baseline BMI measurement. ${ }^{17,40}$ Most of the cohort studies included in the final meta-analysis did not consider any limitation or additional adjustment for depression at baseline, however, the study that contributed the largest number in the total population of this synthesis ${ }^{20}$ excluded men with a diagnosis of depression at the baseline of the study and showed significantly increased odds ratios for underweight on subsequent depression. Moreover, in our study, the magnitude of the association between obesity and depression did not significantly differ across different study designs. However, the magnitude of association between underweight and depression increased in the cross-sectional studies compared with the cohort studies. It is known that there is a significant association between psychological distress and the perception of being underweight, ${ }^{53}$ and it is possible that people who developed depression as a result of psychological distress may recall their weight as less than it actually is. Nevertheless, the pooled odds ratios from the cohort studies showed a significantly increased risk for depression in the underweight population.

Being underweight increased the risk or likelihood of depression regardless of gender. In contrast to a large number of studies that investigated the mechanisms that underlie the association between obesity and depression, there are relatively few studies that support the relationship between underweight and depression. Yu et al have suggested that people who are underweight may have 


\begin{tabular}{|c|c|c|c|c|c|c|}
\hline & $\begin{array}{c}\text { Studies, } n \\
\text { (participants) }\end{array}$ & OR $(95 \% \mathrm{Cl})$ & Q-statistic & $\begin{array}{c}P, \\
\text { heterogeneity }\end{array}$ & $I^{2}$ & $\begin{array}{l}P \text {, between } \\
\text { groups }\end{array}$ \\
\hline \multicolumn{7}{|l|}{ Cohort study, $\geqslant 30 \mathrm{~kg} / \mathrm{m}^{2}$} \\
\hline Overall studies & $6(1285890)$ & $1.13(0.96-1.34)$ & 39.23 & $<0.001$ & 82.2 & \\
\hline \multicolumn{7}{|l|}{ Subgroup analysis } \\
\hline Gender & & & & & & 0.111 \\
\hline Men & $6(1209455)$ & $1.03(0.82-1.30)$ & 27.47 & $<0.001$ & 81.8 & \\
\hline Women & $5(76435)$ & $1.26(1.15-1.38)$ & 2.51 & 0.643 & 0.0 & \\
\hline Depression definition & & & & & & 0.095 \\
\hline DSM or ICD based & $2(1167672)$ & $0.94(0.69-1.27)$ & 8.97 & 0.003 & 88.9 & \\
\hline Other self-reported & $4(118218)$ & $1.23(1.13-1.33)$ & 3.24 & 0.664 & 0.0 & \\
\hline Continent & & & & & & 0.848 \\
\hline North America & 2 (48 201) & $1.20(0.95-1.53)$ & 2.52 & 0.283 & 20.7 & \\
\hline Europe & $4(111444)$ & $1.23(1.13-1.33)$ & 3.23 & 0.519 & 0.0 & \\
\hline \multicolumn{7}{|l|}{ Cross-sectional (adult), $\geqslant 30 \mathrm{~kg} / \mathrm{m}^{2}$} \\
\hline Overall studies & $26(548407)$ & $1.18(1.11-1.26)$ & 255.57 & $<0.001$ & 82.8 & \\
\hline \multicolumn{7}{|l|}{ Subgroup analysis } \\
\hline Gender & & & & & & 0.003 \\
\hline Men & 13 (231219) & $1.07(0.95-1.19)$ & 30.35 & 0.004 & 57.2 & \\
\hline Women & 12 (159521) & $1.41(1.23-1.63)$ & 58.99 & $<0.001$ & 79.7 & \\
\hline Depression definition & & & & & & 0.572 \\
\hline DSM or ICD based & $8(176510)$ & $1.16(1.02-1.32)$ & 68.81 & $<0.001$ & 86.9 & \\
\hline Other self-reported & 18 (371 897) & $1.29(1.18-1.42)$ & 166.41 & $<0.001$ & 82.0 & \\
\hline Continent & & & & & & 0.314 \\
\hline North America & $13(265402)$ & $1.27(1.16-1.39)$ & 149.7 & $<0.001$ & 85.3 & \\
\hline Europe & $3(202028)$ & $1.14(1.00-1.30)$ & 19.77 & 0.001 & 79.8 & \\
\hline Middle East & $1(294)$ & $2.36(0.90-6.23)$ & & & & \\
\hline Asia & $5(37503)$ & $1.45(1.04-2.01)$ & 11.20 & 0.082 & 46.4 & \\
\hline Oceania & $3(43180)$ & $1.06(0.62-1.79)$ & 64.06 & $<0.001$ & 93.8 & \\
\hline \multicolumn{7}{|l|}{ Cross-sectional (adult), $\geqslant 40 \mathrm{~kg} / \mathrm{m}^{2}$} \\
\hline Overall studies & $3(155663)$ & $1.59(1.12-2.24)$ & 19.51 & 0.001 & 79.5 & \\
\hline $\begin{array}{l}1 \text { study (Beydoun \& Wang, 2010) })^{50} \text { excluded } \\
\text { Subgroup analysis }\end{array}$ & $2(153446)$ & $1.56(1.18-2.08)$ & 9.68 & 0.008 & 79.3 & \\
\hline Gender & & & & & & 0.268 \\
\hline Men & $2(82857)$ & $0.51(0.06-4.14)$ & 6.78 & 0.009 & 85.3 & \\
\hline Women & $2(64033)$ & $1.76(0.99-3.13)$ & 2.04 & 0.153 & 51.0 & \\
\hline
\end{tabular}

a negative body image and that their low self-esteem is correlated with depressive symptoms. ${ }^{54}$ In certain societies, being underweight may render a negative body image and increase the possibility of depression in men. ${ }^{18}$ However, women who were underweight also showed an increased risk of depression in this study, and there may be potential underlying biological factors in this relationship. It is possible that low levels of leptin can influence the association between low body weight and depression. Leptin levels are decreased in people with low BMI. ${ }^{55}$ In addition, leptin is regarded as an effective antidepressant, and there is a strong correlation between low leptin levels and depressive symptoms. ${ }^{56}$

In this study, obesity increased the risk for depression in a dose-response manner and this finding is consistent with a previous meta-analysis. ${ }^{2}$ In overweight and obese populations, the results show gender differences. It seems that the current ideal of thinness affects women more than their male counterparts ${ }^{57}$ and causes more psychological distress in women, which can, in turn, lead to depression. In contrast, men who are overweight showed a significantly decreased risk of depression. Previous research ${ }^{48}$ has proposed the 'jolly fat hypothesis', which originally asserted that high body weight is negatively associated with depressive symptoms in men. ${ }^{58}$

Furthermore, some results differed between continents of residence. These different results reflect that the relationship between body size and depression may be influenced by cultural conception of the ideal body weight and related social pressures on the relationship between body size and depression.

Whereas there were no differences in the risk/likelihood of depression in people who were underweight based on the definitions of depression, differences were detected in the overweight/obese group. In both cohort and cross-sectional studies, people who were overweight and obese with self-reported depression showed a higher increase in odds ratios compared with those with depression confirmed by clinical diagnosis. It is possible that being overweight/obese provoked a subjective depressive mood, whereas it had less influence on the development of clinical depression.

\section{Limitations}

In interpreting the findings of this study, several limitations should be considered. First, we only included published studies. Additionally, although we contacted the authors for missing data, we did not receive information from any of the authors. It is possible that the unpublished studies or missing data might cause publication bias. However, the results of Egger's tests suggest that most of the results did not show such bias. Second, although we used fully adjusted estimates where possible for meta-analysis, there is still a chance of residual confounders in each of the studies. Therefore, the true magnitude of the effect of body size, weight change and depression is unknown. However, because the previous metaanalysis only adjusted for age and gender, ${ }^{2}$ this study considered various other factors, such as lifestyle factors or other major illnesses. Third, ascertainment of depression was mostly conducted based on individual's reports and this may reflect a reporting bias. It is known that people tend to underreport their mental illness in surveys, especially in retrospective settings. ${ }^{59}$ Findings in crosssectional studies may be more greatly affected by this reporting 
bias. Finally, there was variation in the covariates adjusted for in each study (Table DS9). In cohort studies, most of the studies adjusted for age and sociodemographic variables and three studies included variables regarding mental health. ${ }^{15,17,41}$ We excluded one study ${ }^{16}$ that did not include sociodemographic factors, but the result was not significantly changed. However, in the cross-sectional studies, there were a number of studies for which we used the numbers directly reported in the articles to calculate crude odds ratios; in these cases we could not conduct additional adjustment for potential covariates. Nevertheless, there was no significant difference compared with our original results when we excluded the studies without any covariates. However, it is possible that the variability in adjustment factors may have led to difference in results. Additionally, there were considerable differences in research methods, sample size, included age groups and gender,depression screening tools and reported effect sizes. These differences might have caused considerable heterogeneity, especially in cross-sectional studies.

\section{Implications}

Despite these limitations, our meta-analysis included a large number of studies and a sufficient amount of data. To our knowledge, this study is the first meta-analysis that has found a significant relationship between underweight and depression. The results cover various study types, such as RCT, cohort and cross-sectional designs. The results showed statistical significance with low heterogeneity, especially in studies with a longitudinal design. Underweight was also considered in relation to depression, and data from other continents, such as Asia, were included in the analysis.

In this meta-analysis, being underweight significantly increased the risk of depression. In addition, the relationship between being overweight and subsequent depression differed between the genders. Obesity significantly increased the risk for depression, and as BMI increased, the risk of depression also increased. The findings of this study suggest that being underweight may also be a risk factor for subsequent depression. In clinical practice, medical care providers should pay attention to the mental health of people who are underweight. Likewise, women who are overweight and obese populations should also be monitored for possible depression.

Sun Jae Jung, MD, PhD, Department of Biomedical Science, Seoul National University College of Medicine, Seoul, Korea; Hyung-taek Woo, MD, Sooyoung Cho, MS, Kyounghoon Park, MD, Seokhun Jeong, MD, Department of Preventive Medicine, Seoul National University College of Medicine, Seoul, Korea; Yu Jin Lee MD, PhD, Department of Psychiatry, Seoul National University Hospital, Seoul, Korea; Daehee Kang, MD, PhD, Department of Biomedical Science, Department of Preventive Medicine, Seoul National University College of Medicine and Cancer Research Institute, Seoul National University, Seoul, Korea; Aesun Shin, MD, PhD, Research Institute, Seoul National University, Seoul, Korea; Aesun Shin, MD, PhD,
Department of Preventive Medicine, Seoul National University college of Medicine and Cancer Research Institute, Seoul National University, Seoul, Korea

Correspondence: Aesun Shin, MD, PhD, Department of Preventive Medicine, Seoul National University College of Medicine, 103 Daehak-ro, Jongno-gu, Seoul 03080, Republic of Korea. Email: shinaesun@snu.ac.kr

First received 21 Apr 2016, final revision 30 Jan 2017, accepted 20 Feb 2017

\section{Funding}

This study was supported by grant 23-2015-0010 from the SNUH Research Fund.

\section{References}

1 Vos T, Flaxman AD, Naghavi M, Lozano R, Michaud C, Ezzati M, et al. Years lived with disability (YLDS) for 1160 sequelae of 289 diseases and injuries 1990-2010: a systematic analysis for the Global Burden of Disease Study 2010. Lancet 2012; 380: 2163-96.

2 Luppino FS, de Wit LM, Bouvy PF, Stijnen T, Cuijpers P, Penninx BW, et al. Overweight, obesity, and depression: a systematic review and meta-analysis of longitudinal studies. Arch Gen Psychiatry 2010; 67: 220-9.
3 Abou Abbas L, Salameh P, Nasser W, Nasser Z, Godin I. Obesity and symptoms of depression among adults in selected countries of the Middle East: a systematic review and meta-analysis. Clin Obes 2015; 5: 2-11.

4 Blaine B. Does depression cause obesity? A meta-analysis of longitudinal studies of depression and weight control. J Health Psychol 2008; 13: 1190-7.

5 Cornette R. The emotional impact of obesity on children. Worldviews Evid Based Nurs 2008; 5: 136-41.

6 Loret de Mola C, de Franca GV, Quevedo L de A, Horta BL. Low birth weight, preterm birth and small for gestational age association with adult depression: systematic review and meta-analysis. Br J Psychiatry 2014; 205 340-7.

7 de Wit L, Luppino F, van Straten A, Penninx B, Zitman F, Cuijpers P. Depression and obesity: a meta-analysis of community-based studies. Psychiatry Res 2010; 178: 230-5.

8 Faith MS, Butryn M, Wadden TA, Fabricatore A, Nguyen AM, Heymsfield SB. Evidence for prospective associations among depression and obesity in population-based studies. Obes Rev 2011; 12: e438-53.

9 Ross CE. Overweight and depression. J Health Soc Behav 1994; 35: 63-79.

10 Higgins JP, Thompson SG, Deeks JJ, Altman DG. Measuring inconsistency in meta-analyses. BMJ 2003; 327: 557-60.

11 Egger M, Davey Smith G, Schneider M, Minder C. Bias in meta-analysis detected by a simple, graphical test. BMJ 1997; 315: 629-34.

12 Kim SY, Park JE, Lee YJ, Seo HJ, Sheen SS, Hahn S, et al. Testing a tool for assessing the risk of bias for nonrandomized studies showed moderate reliability and promising validity. J Clin Epidemiol 2013; 66: 408-14.

13 World Health Organization. Physical Status: The Use and Interpretation of Anthropometry. Report of a WHO Expert Committee. World Health Organization, 1995.

14 Wittchen HU. Reliability and validity studies of the WHO-Composite International Diagnostic Interview (CIDI): a critical review. J Psychiatr Res 1994; 28: 57-84

15 Bjerkeset O, Romundstad P, Evans J, Gunnell D. Association of adult body mass index and height with anxiety, depression, and suicide in the general population: the HUNT study. Am J Epidemiol 2008; 167: 193-202.

16 Geoffroy MC, Li L, Power C. Depressive symptoms and body mass index: co-morbidity and direction of association in a British birth cohort followed over 50 years. Psychol Med 2014; 44: 2641-52.

17 Gaskin JL, Pulver AJ, Branch K, Kabore A, James T, Zhang J. Perception or reality of body weight: which matters to the depressive symptoms. J Affect Disord 2013; 150: 350-5

18 Herva A, Laitinen J, Miettunen J, Veijola J, Karvonen JT, Laksy K, et al. Obesity and depression: results from the longitudinal Northern Finland 1966 Birth Cohort Study. Int J Obes (Lond) 2006; 30: 520-7.

19 Tanaka H, Sasazawa Y, Suzuki S, Nakazawa M, Koyama H. Health status and lifestyle factors as predictors of depression in middle-aged and elderly Japanese adults: a seven-year follow-up of the Komo-Ise cohort study. BMC Psychiatry 2011; 11: 20

20 Batty GD, Whitley E, Kivimaki M, Tynelius P, Rasmussen F. Body mass index and attempted suicide: Cohort study of 1,133,019 Swedish men. Am J Epidemiol 2010; 172: 890-9.

21 Chen $Y$, Jiang $Y$, Mao $Y$. Association between obesity and depression in Canadians. J Womens Health (Larchmt) 2009; 18: 1687-92.

22 Kim DS, Kim HS, Cho Y, Cho SI. The effects of actual and perceived body weight on unhealthy weight control behaviors and depressed mood among adult women in Seoul, Korea. J Prev Med Public Health 2008; 41: 323-30.

23 Ohayon MM, Hong SC. Prevalence of major depressive disorder in the general population of South Korea. J Psychiatr Res 2006; 40: 30-6.

24 Onyike CU, Crum RM, Lee HB, Lyketsos CG, Eaton WW. Is obesity associated with major depression? Results from the Third National Health and Nutrition Examination Survey. Am J Epidemiol 2003; 158: 1139-47.

25 Osborn CY, Patel KA, Liu J, Trott HW, Buchowski MS, Hargreaves MK, et al. Diabetes and co-morbid depression among racially diverse, low-income adults. Ann Behav Med 2011; 41: 300-9.

26 Subramaniam M, Picco L, He V, Vaingankar JA, Abdin E, Verma S, et al. Body mass index and risk of mental disorders in the general population: results from the Singapore Mental Health Study. J Psychosom Res 2013; 74: 135-41.

27 Taylor KL, Hadgkiss EJ, Jelinek GA, Weiland TJ, Pereira NG, Marck CH, et al. Lifestyle factors, demographics and medications associated with depression risk in an international sample of people with multiple sclerosis. BMC Psychiatry 2014; 14: 327

28 Carey $\mathrm{M}$, Small $\mathrm{H}$, Yoong SL, Boyes A, Bisquera A, Sanson-Fisher R. Prevalence of comorbid depression and obesity in general practice: a cross-sectional survey. Br J Gen Pract 2014; 64: e122-7. 
29 Guruprasad KG, Niranjan MR, Ashwin S. A study of association of depressive symptoms among the type 2 diabetic outpatients presenting to a tertiary care hospital. Indian J Psychol Med 2012; 34: 30-3.

30 Joseph N, Unnikrishnan B, Raghavendra Babu YP, Kotian MS, Nelliyanil M. Proportion of depression and its determinants among type 2 diabetes mellitus patients in various tertiary care hospitals in Mangalore city of South India. Indian J Endocrinol Metab 2013; 17: 681-8.

31 Liu Y, Al-Sayegh H, Jabrah R, Wang W, Yan F, Zhang J. Association between C-reactive protein and depression: modulated by gender and mediated by body weight. Psychiatry Res 2014; 219: 103-8.

32 McLaren L, Beck CA, Patten SB, Fick GH, Adair CE. The relationship between body mass index and mental health. A population-based study of the effects of the definition of mental health. Soc Psychiatry Psychiatr Epidemiol 2008; 43: 63-71.

33 Smith TJ, White A, Hadden L, Young AJ, Marriott BP. Associations between mental health disorders and body mass index among military personnel. Am J Health Behav 2014; 38: 529-40.

34 Ul-Haq Z, Smith DJ, Nicholl BI, Cullen B, Martin D, Gill JM, et al. Gender differences in the association between adiposity and probable major depression: a cross-sectional study of 140,564 UK Biobank participants. BMC Psychiatry 2014; 14: 153.

35 Jorm AF, Korten $A E$, Christensen $H$, Jacomb PA, Rodgers B, Parslow RA. Association of obesity with anxiety, depression and emotional well-being: a community survey. Aust NZ J Public Health 2003; 27: 434-40.

36 Goldney RD, Dunn KI, Air TM, Dal Grande E, Taylor AW. Relationships between body mass index, mental health, and suicidal ideation: population perspective using two methods. Aust NZ J Psychiatry 2009; 43: 652-8.

37 Kim JY, Chang HM, Cho JJ, Yoo SH, Kim SY. Relationship between obesity and depression in the Korean working population. J Korean Med Sci 2010; 25: 1560-7.

38 Sorberg A, Gunnell D, Falkstedt D, Allebeck P, Aberg M, Hemmingsson T. Body mass index in young adulthood and suicidal behavior up to age 59 in a cohort of Swedish men. PLOS One 2014; 9: e101213.

39 Kress AM, Peterson MR, Hartzell MC. Association between obesity and depressive symptoms among U.S. Military active duty service personnel, 2002. J Psychosom Res 2006; 60: 263-71.

40 Pickering RP, Goldstein RB, Hasin DS, Blanco C, Smith SM, Huang B, et al. Temporal relationships between overweight and obesity and DSM-IV substance use, mood, and anxiety disorders: results from a prospective study, the National Epidemiologic Survey on Alcohol and Related Conditions. J Clin Psychiatry 2011; 72: 1494-502.

41 Wild B, Herzog W, Lechner S, Niehoff D, Brenner H, Muller H, et al. Gender specific temporal and cross-sectional associations between $\mathrm{BMI}$-class and symptoms of depression in the elderly. J Psychosom Res 2012; 72: 376-82.

42 Ohayon MM. Epidemiology of depression and its treatment in the general population. J Psychiatr Res 2007; 41: 207-13.

43 Sweileh WM, Abu-Hadeed HM, Al-Jabi SW, Zyoud SH. Prevalence of depression among people with type 2 diabetes mellitus: a cross sectional study in Palestine. BMC Public Health. 2014; 14: 163
44 Egede LE, Zheng D. Independent factors associated with major depressive disorder in a national sample of individuals with diabetes. Diabetes Care 2003; 26: 104-11.

45 Gearhardt AN, Harrison EL, McKee SA. Does co-morbid depression alter the inverse relationship between obesity and substance use disorders? Drug Alcohol Depend 2012; 124: 185-8.

46 Lincoln KD, Abdou CM, Lloyd D. Race and socioeconomic differences in obesity and depression among Black and non-Hispanic White Americans. $J$ Health Care Poor Underserved 2014; 25: 257-75.

47 Grundy A, Cotterchio M, Kirsh VA, Kreiger N. Associations between anxiety, depression, antidepressant medication, obesity and weight gain among Canadian women. PLoS One 2014; 9: e99780.

48 Palinkas LA, Wingard DL, Barrett-Connor E. Depressive symptoms in overweight and obese older adults: a test of the "jolly fat" hypothesis. J Psychosom Res 1996; 40: 59-66.

49 Heo M, Pietrobelli A, Fontaine KR, Sirey JA, Faith MS. Depressive mood and obesity in US adults: comparison and moderation by sex, age and race. Int J Obes (Lond) 2006; 30: 513-9.

50 Beydoun MA, Wang Y. Pathways linking socioeconomic status to obesity through depression and lifestyle factors among young US adults. J Affect Disord 2010; 123: 52-63.

51 Tully PJ, Baumeister $H$, Bengel J, Jenkins A, Januszewski A, Martin S, et al. The longitudinal association between inflammation and incident depressive symptoms in men: the effects of hs-CRP are independent of abdominal obesity and metabolic disturbances. Physiol Behav 2015; 139: 328-35.

52 Lawlor DA, Bedford C, Taylor M, Ebrahim S. Agreement between measured and self-reported weight in older women. Results from the British Women's Heart and Health Study. Age Ageing 2002; 31: 169-74.

53 Atlantis E, Ball K. Association between weight perception and psychological distress. Int J Obes (Lond) 2008; 32: 715-21.

54 Yu NW, Chen $\mathrm{CY}$, Liu CY, Chau YL, Chang CM. Association of body mass index and depressive symptoms in a Chinese community population: results from the Health Promotion Knowledge, Attitudes, and Performance Survey in Taiwan. Chang Gung Med J 2011; 34: 620-7.

55 Jequier E. Leptin signaling, adiposity, and energy balance. Ann NY Acad Sci 2002; 967: 379-88.

56 Lawson EA, Miller KK, Blum Jl, Meenaghan E, Misra M, Eddy KT, et al. Leptin levels are associated with decreased depressive symptoms in women across the weight spectrum, independent of body fat. Clin Endocrinol (Oxf) 2012; 76: $520-5$.

57 Kiefer I, Leitner B, Bauer R, Rieder A. Body weight: the male and female perception. Soz Praventivmed 2000; 45: 274-8.

58 Crisp AH, McGuiness B. Jolly fat: relation between obesity and psychoneurosis in general population. BMJ 1976; 1: 7-9.

59 Takayanagi Y, Spira AP, Roth KB, Gallo JJ, Eaton WW, Mojtabai R. Accuracy of reports of lifetime mental and physical disorders: results from the Baltimore Epidemiological Catchment Area study. JAMA Psychiatry 2014; 71: 273-80.

EXTRA 